Revista de la red interuniversitaria de estudios sobre las literaturas rioplatenses contemporáneas en Francia

$21 \mid 2020$

Glosolalias transplatinas: fantasmas, utopías y

ficciones lingüísticas

\title{
Escribir en lenguas
}

Écrire en langues

Writing in Tongues

Martín Arias and Diego Vecchio

\section{(2) OpenEdition}

\section{Journals}

Electronic version

URL: http://journals.openedition.org/lirico/9916

DOI: $10.4000 /$ lirico.9916

ISSN: 2262-8339

Publisher

Réseau interuniversitaire d'étude des littératures contemporaines du Río de la Plata

Electronic reference

Martín Arias y Diego Vecchio, «Escribir en lenguas», Cuadernos LIRICO [En línea], 21 | 2020, Publicado el 12 julio 2020, consultado el 29 enero 2021. URL: http://journals.openedition.org/lirico/9916 ; DOI: https://doi.org/10.4000/lirico.9916

This text was automatically generated on 29 January 2021.

\section{(ब) $(\Theta \Theta$}

Cuadernos LIRICO está distribuido bajo una Licencia Creative Commons Atribución-NoComercialSinDerivar 4.0 Internacional. 


\title{
Escribir en lenguas
}

\author{
Écrire en langues \\ Writing in Tongues
}

\section{Martín Arias and Diego Vecchio}

1 Don del Espíritu, medio de comunicación privilegiado con las inteligencias ultramundanas desprovistas de boca, lengua y laringe, naufragio del lenguaje por culpa de un significante forcluido, descomposición del lenguaje después de una lesión cerebral, lengua que se repliega en su pura materialidad sonora hasta alcanzar el lenguaje que precedió al lenguaje, artefacto lúdico para divertir a los niños y sobre todo a las niñas, la glosolalia surge en una encrucijada entre las experiencias mágicomístico-religiosas, las ciencias y la literatura.

\section{Hablar en glosas}

2 Cada religión inventa su propia lengua sagrada: el hinduismo, el sánscrito; el judaísmo, el hebreo. El cristianismo no fue una excepción. ¿Pero qué lengua sagrada era posible inventar en un imperio postbabélico, para comunicar un mensaje universal, destinado ya no a una casta o a un pueblo, sino a toda la humanidad? Para compensar los estragos de Yahvé, que en uno de sus tantos arranques de furia confundió las lenguas, el Espíritu tuvo que repartir un carisma de una lengua que borrara las diferencias entre la lengua materna y las lenguas extranjeras, que todo el mundo pudiera hablar y comprender a la vez.

3 En los Hechos de los Apóstoles (2, 1-13), Lucas, el más novelesco de los cuatro evangelistas, refiere que cincuenta días después de la Resurrección, los discípulos se hallaban reunidos, cuando de repente se oyó un ruido como el de una impetuosa ráfaga de viento y aparecieron unas lenguas como de fuego que se posaron sobre cada uno de ellos. Los discípulos quedaron todos llenos del Espíritu Santo y se pusieron a hablar en otras lenguas, según el Espíritu les concedía expresarse.

Residían en Jerusalén hombres piadosos, venidos de todas las naciones que hay bajo el cielo. Al producirse aquel ruido la gente se congregó y se llenó de estupor porque cada uno les oía hablar en su propia lengua. Estupefactos y admirados decían: “Es 
que no son galileos todos estos que están hablando? Pues ¿cómo cada uno de nosotros les oímos en nuestra propia lengua nativa: partos, medos y elamitas; los que habitamos en Mesopotamia, Judea y Capadocia, el Ponto, Asia, Frigia y Panfilia, Egipto y la parte de Libia fronteriza con Cirene; los romanos residentes aquí, tanto judíos como prosélitos, cretenses y árabes, los oímos proclamar en nuestras lenguas las maravillas de Dios?". Todos estaban estupefactos y perplejos, y se decían unos a otros: “¿Qué significa esto?”. Otros en cambio decían riéndose: “Están llenos de mosto" (Biblia 1999: 1512-3).

4 La embriaguez de Pentecostés es el negativo del castigo de Babel. Si "el impulso disyuntivo de Babel", como escribe Haroldo de Campos (160), despliega el mito de la pérdida de la lengua universal, de su pulverización y derrumbe en una multiplicidad lingüística que confunde y aturde, el "soplo conjuntivo de Pentecostés" formula la utopía de una lengua transmaterna, ya no para volver a la unidad original, puesto que esta unidad está irremediablemente perdida, sino para imaginar, en un imperio políglota que tiende a confundirse con el mundo, una comunidad lingüística imposible.

5 Esta lengua transmaterna exotérica destinada a aquellos que no pertenecen a la asamblea y hablan otros idiomas, coexiste, en las primeras comunidades cristianas, con una lengua panextranjera esotérica que consiste en pronunciar y articular, en el seno de la asamblea, sonidos ininteligibles para comunicarse directamente con Dios. Esta lengua privada resulta impenetrable para los otros y en ciertos casos hasta para el mismo orante. A diferencia del mero ruido, esta lengua incomprensible pretende decir algo; y este algo que se escapa y se escabulle define su especificidad. La glosolalia es una lengua sin sentido y por ello mismo capaz de todos los sentidos. Todo es cuestión de interpretación y traducción. Si el griego $\gamma \lambda \omega \tilde{\sigma} \sigma \alpha \alpha$ (glōssa) quiere decir lengua o lenguaje, el latín glossa designa tanto la palabra rara y de sentido oscuro como su explicación. Hablar en lenguas significa hablar en glosas.

6 La glosolalia plantea, desde los comienzos, el problema del sujeto: el sujeto que habla sin saber lo que dice y los sujetos que lo oyen sin entender. En la Primera Epístola a los Corintios, consciente de los peligros del solipsismo glosolálico, Pablo advierte que "el que habla en lenguas no habla a los hombres sino a Dios. En efecto, nadie le entiende: dice en espíritu cosas misteriosas" $(14,2)$. Por ello, recomienda que "si se habla en lenguas, que hablen dos, o a lo más, tres, y por turno; y que haya un intérprete. Si no hay quien interprete, guárdese silencio en la asamblea; hable cada cual consigo mismo y con Dios" $(14,27-28)$. La palabra utilizada por Pablo para "interpretar" no es hermeneúo, sino diermeneúo, que incluye el prefijo diá, el cual indica acabamiento, es decir, es necesario que el habla extática en glosas sea interpretada completamente, sin resto, sin reservas de sentido, sin secretos entre el orante y sus hermanos en Cristo.

\section{Glo'xugo}

7 Dieciocho siglos más tarde, en la era del desencantamiento, el repliegue del cristianismo de la esfera pública no deja de tener efectos sobre el hablar en lenguas. En la nebulosa ocultista, espiritista y teosófica, las experiencias glosolálicas son una vía de acceso a los ultramundos invisibles, astrales o celestes. La glosolalia se convierte en lengua espectral, a través de la cual ya no habla el Espíritu, sino las diversas familias de espíritus. 
8 En el siglo XVIII, Emanuel Swedenborg viaja de planeta en planeta y tiene la oportunidad de conversar con los ángeles, provistos de boca, dientes y lengua y por ende de varios idiomas en perfecta consonancia con los sentimientos y las ideas.

Las palabras de los ángeles celestiales -escribe Swedenborg- son como una corriente ligera, suave y virtualmente continua, mientras que las de los ángeles espirituales son algo más sonoras y vigorosas. Además, las vocales $U$ y $O$ tienden a predominar en el habla de los ángeles celestiales, mientras que entre los ángeles espirituales son la $E$ y la $I$ las vocales más frecuentes. Las vocales representan el sonido y en el sonido están los sentimientos; pues como ya señalamos, el sonido del habla de los ángeles responde a sus sentimientos, y las articulaciones del sonido, o palabras, corresponden a las ideas individuales que resultan de sus sentimientos (2002: 238-239).

9 La teosofía también inventa su lengua sagrada, abriéndose a las espiritualidades de Oriente. Helena Blavatsky escribe Isis sin velos copiando lo que le dictan telepáticamente sus Maestros desde el Tíbet. Las mil quinientas páginas de La doctrina secreta pretenden ser la traducción comentada de un supuesto libro esotérico (el Libro de Dzyan) escrito en una lengua desconocida (el senzar). La doctrina secreta se publica en Londres, en 1888.

10 Tres décadas después, la sociedad londinense aún estaba fascinada por las enseñanzas teosóficas cuando llega a ella el joven argentino Schulz Solari, quien, según los archivos del Pan Klub de Buenos Aires, participó hacia 1919 de actividades esotéricas en Londres. Entre los dudosos místicos que por aquellos días acechaban en esa ciudad se encontraba Aleister Crowley, cuyas investigaciones sobre la mística judía fueron descritas por Scholem (2) como "muy coloridas patrañas" y cuya imagen causaría sensación en la música popular del siglo veinte, desde los Beatles hasta Ozzy Osbourne. Pero no sería en Londres, sino en París, donde cinco años después Crowley iniciaría a Xul en los misterios de una hermandad esotérica llamada Astrum Argentum. Como parte de su iniciación, el inglés transmitió a su alumno sudamericano un método de exploración espiritual, una suerte de sistema de ejercicios mentales destinados a inducir, en quien lo practicase, visiones místicas. El practicante estaba obligado, además, a dejar un registro escrito de su experiencia. Como sabemos por la correspondencia conservada por Xul, Crowley le pidió que al aplicar el método utilizara el I Ching, el antiguo libro adivinatorio chino, mandato que consta en el diario personal de Xul: "reescribir el I Ching describiendo cada hexagrama por medio de una pura visión. Hacer 64 dibujos simbólicos de prosa corta o descripciones poéticas". El pintor retornó a Buenos Aires, donde aplicó el método. Existen registros de sus visiones desde 1924, y sabemos que, hacia 1937, planeó una publicación de esos textos bajo el título de San Signos. Ahora bien, a las instrucciones de Crowley, Xul añadió un elemento nuevo. Se trata del idioma de estas "prosas cortas". Redactadas al comienzo en inglés, luego traducidas al castellano, a partir de cierto momento todas fueron retraducidas por el autor a una lengua de su invención.

11 El neocriollo o criol, el idioma en que las visiones obtenidas con el método Crowley fueron registradas, se presenta como un festín de aglutinaciones, o para usar las palabras de Xul, como una glea, un conglomerio, un glo'xugo (jugo de lenguas, según traduce Daniel Nelson). Por momentos, tenemos la impresión de asistir a una biblioteca de Babel preborgeana, o bien a un museo de la vanguardia. Así, el 30 de septiembre de 1935 a las 13h, Xul contempla "trunkiescenas de 'mansuerte hen múndaqes calmos. me parezan inmensos depósitos de novelas en fragmos bitradúcioas en suiplasias afiniquntas" ("escenas truncadas de la suerte humana en escenarios mundanos 
tranquilos. me parecen inmensos despósitos de novelas fragmentadas traducidas espiritualmente en formas especiales agrupadas según sus afinidades"). Además, como observa Alfredo Rubione (39) aproximando los San Signos al Girondo masmedular (a quien alguna vez el malicioso Borges acusó de plagiar a Xul), el neocriollo sirve a la experiencia erótica. El diario, en efecto, también se lee como un catálogo de "partes $i$ órganos del divicuerpo". El 10 de noviembre de 1925 a las $11.30 \mathrm{~h}$, la consciencia de Xul Solar se posa en el estómago de un ángel azul que "jerge su virvergu mo asta du ke chorri colge blan' bandera de plurgotas. sou un chinégrito currukio en su épigastro. él bokiaspire aire que cul'pede pos. avezes nus पúndamo [pronúnciese "júndamo"], otras vuelamo per avánzamo rá, por vela i cul'sóplido" ("yergue su miembro viril como un asta de la que cuelga chorreando una bandera blanca de múltiples gotas. soy un negrito chiquitito acurrucado en la parte de arriba de su estómago. él aspira por la boca aire que después tira como pedos por el culo. a veces nos hundimos; otras veces volamos, pero avanzamos rápidamente por la vela y por el culo que sopla"). Por lo demás, aquí todo es chorreante y móvil. Las letras son movigramas, las visiones están pobladas de fluomes (hombres fluidos) y Xul pasea por airiř́os, "ríos aéreos" en la traducción de Nelson, quizá demasiado literal, pues si se tiene en cuenta tanto la notoria presencia del portugués como el despliegue erótico, ¿no habría que decir, más bien, aguas aéreas?

\section{Las glosolalias y el inconsciente}

12 Estas glosolalias místicas o encantadas coexisten, no sin fricción, con glosolalias vaciadas de toda dimensión mágica o religiosa, como las patologías del lenguaje que estudian los psiquiatras, psicólogos, lingüistas y psicoanalistas, cuando el glosólalo se convierte en afásico o psicótico. Transformado en objeto epistémico, el hablar en lenguas puede ser un signo de una lesión cerebral, que afecta el aérea del lenguaje; o una de las tantas formas del delirio, con su lado negativo (la desintegración del lenguaje, la destrucción de la sintaxis, el derrumbe del sentido) y su lado positivo (la proliferación de neologismos, la invención de mundos, la emancipación de la imaginación).

13 El ejemplo más representativo de esta fricción lo constituye la médium Catherine-Élise Müller, más conocida por el pseudónimo de Hélène Smith, quien, sumida en un estado de sonambulismo, fabrica hacia fines del siglo XIX simulacros de lenguas, con enunciados privados de sentido pero no sin verosimilitud fonética, a tal punto que suscita en quienes asisten a sus sesiones la creencia de oír una lengua natural. A través de la voz de Simandini, una princesa árabe del siglo XV que desposa a un príncipe hindú, Hélène Smith balbucea algunas palabras de sánscrito, lengua que nunca aprendió. Siguiendo los pasos de Swedenborg y de Flammarion, también se aventura en una travesía transplanetaria hasta Marte, donde sus habitantes la inician en los rudimentos de la lengua marciana y ultramarciana. La glosolalia, que irrumpe en estos estados de sonambulismo, es a su vez acompañada por una "novela" que la vuelve interpretable. Sobre este caso, Théodore Flournoy escribe una monografía publicada el mismo año que la Interpretación de los sueños de Freud, con el título Des Indes à la planète Mars.

A través de estos lenguajes desquiciados, comienza a hablar el inconsciente. No mucho después, Jacques Lacan, el glosólalo, iniciará su carrera de psiquiatra con las 
"esquizografías", y terminará su vida de psicoanalista con Joyce, le sinthome, seducido por el canto de sirenas embriagadas de Finnegans Wake.

\section{Lengua universal, inanidad sonora}

En el mundo secularizado y desencantado de comienzos del siglo veinte, la literatura también se apodera de la experiencia glosolálica para confeccionar lenguas de incomunicación que nadie habla ni entiende, que no significan nada a no ser el sentido que irrumpe desde el sinsentido, cuando el lenguaje se transforma en ruido. El zaum, la lengua transracional de los futuristas rusos, cultivada por Kruchenykh y Khlebnikov y teorizada por los formalistas en busca de su literaturnost, así como las humoradas verbales de Hugo Ball en el Cabaret Voltaire, amenazaban con glosolalizar Europa.

En 1922, meses antes de que Joyce comenzara su Work in Progress, Vallejo publica Trilce $\mathrm{y}$, desde el título, disuelve el sentido en una irreparable afrenta fónica: "Rumbbb... Trrrapprrrr rrach... chaz / Serpentínica u del bizcochero / engirafada al tímpano" (41). Algunos años después, en las páginas de la revista francesa Transition, las primicias del Wake joyceano se mezclan no solo con la escritura en lenguas dadaísta de Ball, sino también con un fragmento de Altazor de Vicente Huidobro ( ${ }^{\circ} 19-20$, junio de 1930) en el que la invención léxica - "descolgada esta mañana de la lunala" (68)- alcanza un paroxismo que, más tarde, volveremos a escuchar en Girondo -"enlunadados muslos de estival epicentro" (226)-.

Estas eclosiones verbales de la primera mitad del siglo veinte pueden verse, sobre todo en su vertiente europea, como el contrapunto de las lenguas artificiales internacionales, idiomas como el volapuk de Martin Schleyer o el esperanto de Ludoviko Lázaro Zamenhof, artefactos lingüísticos fabricados de manera voluntaria para allanar las comunicaciones de la era post-babélica y fundar, una vez más, una comunidad lingüística imposible. En verdad, la efervescencia pentecostal de las lenguas universales provenía del siglo anterior, pues como explica Rubione a propósito del utopismo xuliano, "de las casi cuatrocientas lenguas artificiales que se inventaron en cuatro siglos, ciento cuarenta y cinco se idearon entre 1880 y 1914, es decir que el cuarenta y cinco por ciento se creó en solamente treinta y cinco años" (38).

En América Latina, la conexión entre la voluntad decimonónica de intervención sobre la lengua y las vanguardias revela matices singulares. Así, del utopismo lingüístico latinoamericano del diecinueve, lo que enlaza con las vanguardias de los años 1920 es el hecho de que estas reactivan las disputas en torno a la lengua americana, esas que ocuparon tanto a Sarmiento como a Simón Rodríguez (Venezuela), a José de Alencar (Brasil) como a González Prada (Perú) -o ya en el borde del novecientos, en Argentina, a Lucien Abeille con su Idioma nacional de los argentinos (1900)-. En este sentido, y para unir las reflexiones de Jorge Schwartz (2002: 55-78) a un tipo de indagación que consagró Amado Alonso en un ensayo publicado en Buenos Aires a fines de los años 1930 -Castellano, Español, Idioma Nacional. Historia espiritual de tres nombres-, recordaremos que los nombres de las lenguas imaginadas en el periodo canónico de las vanguardias latinoamericanas -el "neocriollo" de Xul, por caso, o la "lengua nacional" de Mário de Andrade, o la "ortografía indoamericana" de Fransisqo Chuqiwanka Ayulo, o aun el "idioma de los argentinos" borgeano- exhibían un impulso ya de alejamiento, ya de intervención más o menos brutal en el "español" y el "portugués", dos lenguas nombradas, si se admite este término de la teoría del translanguaging que nos advierte, 
oportunamente, que no todas lo son. En el caso del neocriollo, Xul parece sugerir que las "lenguas nombradas son objetos sociales, no lingüísticos"; "sus fronteras y la pertenencia a ellas no pueden establecerse sobre la base de rasgos léxicos o estructurales", sino solo a partir de los bordes "social y políticamente definidos de las leguas nombradas (usualmente nacionales o estatales)" (García, Otheguy y Reid 2015: 281). En San Signos, una palabra puede "pertenecer" a una lengua o a varias, lo cual equivale a devastar el concepto mismo de lengua.

En este sentido, si en lugar de volvernos hacia el siglo diecinueve, nos dirigimos hacia finales del veinte, podemos pensar en un Néstor Perlongher irónicamente apologético hablando en portuñol ante un público de profesores de castellano en São Paulo: "Las veces que tengo que discursear en portugués suelo comenzar disculpándome por el hecho de proceder a una destrucción simultánea de dos lenguas..." (2004: 247, las itálicas son nuestras). Pero lo que así se destruye, como precisará después el poeta, son las lenguas constituidas, es decir, los idiomas en tanto que objetos delimitados. Estamos ante una verdadera "crítica de la lengua", la misma que había sido emprendida, en el corazón secreto de las vanguardias, por Xul Solar. Cierto es que a diferencia de la lengua neobarroca de Perlongher, Xul imaginaba para la suya un destino que, menos que una "expresión americana" lezamesca, era el de una comunicación latinoamericana. Pero no es menos cierto, como indica uno de sus lectores de Xul, que entre las contradicciones del neocriollo se encuentra el hecho de que "si por un lado se trata de una lengua vehicular sudamericana cuya utilización llevaría a la confraternización entre los pueblos, por otro, su carácter ocultista se dirige hacia lo que Macedonio Fernández llegó a denominar, irónicamente, lengua de la incomunicación" (Schwartz 2005: 43). Una fuga del sentido se abre así en el neocriollo, idioma situado en algún punto incierto, más bien joyceano, entre las lenguas universales, con sus bellas aspiraciones humanistas, y los alaridos payasescos de Hugo Ball. Lo que Antelo llamaría la armonía grotesca de Babel: entre el soplo conjuntivo de Pentecostés y la inanidad sonora.

\section{La imaginación uglósica: de Borges al comarquí}

Como señala Rubione (37), el magisterio de Xul en la teoría lingüística del primer Borges ("El idioma infinito", El idioma de los argentinos) difícilmente podría subestimarse. Pero Borges, atento a las exigencias de la miniatura literaria, suele definir sus conjuntos por comprensión, y en lugar de desplegar ante los ojos una lengua imaginaria, se limita al gesto no retiniano de indicar las propiedades comunes de sus elementos (la ausencia de sustantivos en la Ursprache de Tlön, etc.). Eso le permite conservar una ambigua distancia, ya presente en Macedonio, ante proyectos como el neocriollo de Xul, que sin embargo también se traman en sus ficciones. -En el siglo siguiente, volveremos a encontrar esa ironía en Daniel Guebel, quien luego de tejer una hipnótica aventura legible en torno de una escritura indescifrada, adjudica a la panlengua xuliana y al actor glosólalo Jorge Bonino el privilegio de ser "antecedentes" del manuscrito Voynich-. Para Sarlo, la fascinación de Borges con las lenguas imaginarias proviene no solo de la posibilidad de que estas sean exactas, impermeables al equívoco, sino de que así puedan resistir "al desorden que inquieta el corazón de las sociedades modernas. Las lenguas reales llevan la marca de la mezcla demográfica, 
especialmente en naciones como la Argentina donde la población hispano-criolla se mezcló, casi por mitades, con los inmigrantes de Europa del sur y central" (119).

Cortázar, en cambio, tiende a definir sus conjuntos lingüísticos por extensión. El capítulo 68 de Rayuela, de irreprochable sintaxis (castellana), testimonia esa pasión glíglica, luego replicada en su neofonema (El libro de Manuel). Para Julio Premat, el glíglico es la "materialización de una imposibilidad expresiva", ya que Cortázar "se quejaba de la pudibundez del discurso literario sobre la sexualidad en la Argentina". Según el crítico, tal situación discursiva cambió de modo duradero con la entrada del "lacanismo de combate" de Literal, y sobre todo de Osvaldo Lamborghini, cuyos textos "redefinen lo decible" (156). La cuestión, entonces, podría formularse en una pregunta en la cual se enlazan historia y política de la lengua, sexo y literatura: ¿cómo leer en glíglico después del comarquí?

\section{Hacia el sótano de los fonemas niños}

En los años 80, Néstor Perlongher entra en escena con sus poemarios abarrocados, en los que asistimos, según Nicolás Rosa, a un "regreso a la foné". Para Rosa, hay aquí un lenguaje en acción que nada tiene que ver con la teoría de los actos de habla, sino con una

acción muscular del lenguaje, hacer que el lenguaje en la acción del verso se ablande, se rigidice, se conmueva en su estatismo, vibre y sonorice en sus reticulaciones, en sus meandros, en sus divertículos, se apague y vuelva a encenderse en sus fluorescencias, caiga hacia sus estratos más profundos, hacia el bajo fondo de la gramática, suene y resuene contra las obligaciones sintácticas, hacia el trasfondo de los 'fonemas lácteos', allí donde la vibrante múltiple sonora (r... r... rr... rrr) desciende hacia el sótano de los fonemas niños, los del murmullo y los de la mamada (mmm... mmm... m), fonología de la leche materna que repercute sordamente en la susurrante glotis. (2006: 129)

La mención de los "fonemas lácteos" y los "fonemas niños" pone en evidencia una de las tantas utopías lingüísticas que plantean las glosolalias, identificadas a los balbuceos y vocalizaciones del lactante o infans (etimológicamente "incapaz de hablar"): el lenguaje en estado embrional, la lengua materna en estado fetal.

En "Tejidos esponjosos" Arturo Carrera recuerda, junto a Alfonso Reyes, que la poesía experimental comienza en América Latina como un juego de niñas glosolálicas, cuando, en la casa del poeta afrancesado Mariano Brull, durante una velada, la mayor de sus hijas recitó un poema escrito especialmente por su padre, en su afán por renovar los géneros manidos. Tal poema decía:

Filiflama alabe cundre

Ala olalúnea alífera

Alveolea jitanjáfora

Liris aslumba salífera (Reyes 1969: 201).

"Eso recitaban esas niñas que nacieron peinadas. $\mathrm{Y}$ esos sonidos pentatónicos de sobremesa favorecieron el divertimento polifónico de los poetas del porvenir" (Carrera 1981: 29). El primero de ellos, Girondo, inventa en En la másmédula "una máquina fonofágica, devoradora de sentido y sonidos" (30), y traza una línea de fuga que se pierde en las escrituras ilegibles de Mirtha Dermisache. Estos grafos que nada dicen, precisamente para decir no a la traducción, a la interpretación y al comentario, parecen 
marcar el récord olímpico del sinsentido: la glosolalia sin glosa- ni -lalia, reducida a un puro esqueleto gráfico.

Arturo Carrera también recuerda que, desde el principio, estos juegos glosolálicos suscitan menos divertimento polifónico que aversión. En la algarabía jitanjafórica de las meninas parisinas de Mariano Brull hay un eco de Alicia que desafía a un hombrehuevo malhumorado, encaramado en una pared, a descifrar el sinsentido de Jabberwocky, el poema compuesto con palabras-valijas, que comprimen varias significaciones en una misma palabra hasta volverla irreconocible. Artaud, que comienza y abandona una versión agramatical de este pasaje de A través del espejo, confiesa en una carta dirigida a Henry Parisot, traductor de Lewis Carroll al francés:

Je n'ai pas fait de traduction de Jabberwocky. J'ai essayé d'en traduire un fragment mais cela m'a ennuyé. Je n'ai jamais aimé ce poème qui m'a toujours paru d'un infantilisme affecté ; j'aime les poèmes jaillis et non les langages cherchés. Je veux, quand j'écris ou je lis, sentir bander mon âme comme dans la Charogne, le Martyr ou le Voyage à Cythère de Baudelaire. Je n'aime pas les poèmes ou les langages de surface et qui respirent d'heureux loisirs et des réussites de l'intellect, celui-ci s'appuyât-il sur l'anus mais sans y mettre de l'âme et du cœur. L'anus est toujours terreur, et je n'admets pas qu'on perde un excrément sans se déchirer d'y perdre aussi son âme, et il n'y a pas d'âme dans Jabberwocky. (1971: 184)

Aquí podríamos recordar la hoy famosa polémica Feiling-Aira en Babel, hace treinta años. En 1988, Arturo Carrera y Emeterio Cerro publican Retrato de un albañil adolescente \& Telones zurcidos para títeres con himen, que incluye versos como: "El titirí sanjónfluvial harapintoespiral obliterado sibilino gá-/ rrulo momio/ el titirí ventiscoso risado capón franjo boscaje alcanfor ignoto/ escintín" (43). Poco después, en las páginas de Babel, C. E. Feiling escribía: "el mogolismo autoinducido de Tzara jamás me pareció interesante y tampoco, una vez pasada la adolescencia, pude encontrar en el surrealismo mayor valor que el de haber dirigido la atención de los lectores hacia figuras como William Beckford [...]. No quisiera, sin embargo, dar la impresión de estar siquiera comparando la irreverente actividad de Tzara o Breton con estos textos de Carrera y Cerro" (1989: 36). Con todo, Feiling reconocía al poeta de Arturo y yo, de quien lamentaba la decisión de "entrar en asociación ilícita" con Cerro. Meses después, en las mismas páginas de Babel, Aira contestaba con un artículo en que la poesía de Emeterio Cerro era elevada a prueba de amor literario: "una prueba que funciona con un automatismo de chip. El que no ama a Emeterio Cerro no ama la literatura". Además de tachar de "biempensantes" a los enemigos del autor de Los teros del Danubio, Aira apostrofaba a todo aquel que desdeñara "estos libritos sin pies ni cabeza que todo el mundo se apresura a descartar como glosolalias taradas y que hacen pensar siempre en el traje nuevo del emperador y el esnobismo pueril de los incapaces" (1990: 41) -ya en el siglo siguiente, podríamos pensar en la defensa por Aira de libros como El Aleph engordado, o de otros, más cercanos a la glosolalia, como El Martín Fierro ordenado alfabéticamente, ambos de Pablo Katchadjian-. En su respuesta, Feiling se lamentaría de haber sido tratado de biempensante, y no, como hubiese preferido, de reaccionario (1990: 7).

Lo cierto es que más allá de su crítica a la infancia o adolescencia lingüística de la vanguardia, Feiling intentaría, junto con Luis Chitarroni, una traducción (fragmentaria, obligadamente) de ese libro en que el habla en glosas es llevada al absoluto de la literatura: Finnegans Wake. La compilación de ensayos Con toda intención recoge un diálogo titulado "El sistema de la doble humillación", fechado en 1992, en que los dos traductores, cuyas identidades se omiten en las réplicas, evocan los devastadores 
efectos que produjo en ellos el trabajo con la lengua de Joyce. Aquí vuelve la palabra "glosolalia", calificada esta vez no de "tarada", sino apenas de "ruidosa":

-...Lo que quiero decir es que la palabra, no la frase, constituye la unidad de sentido del Finnegans. Me asustan, por otra parte, las secuelas que nos dejaba el trabajo. Después de cuatro o cinco horas de traducción, éramos impresentables.

-Eso está relacionado con la tiranía de Joyce y su contagio. Cuando traducíamos, el Finnegans era una especie de modelo férreo. Luego empezaba a ser un repertorio de procedimientos verbales inútiles para la vida cotidiana. Tal vez no fuese un método dichoso: primero permanecíamos en silencio con el texto frente a nuestros ojos (cuatro o cinco horas = dos o tres líneas); después, bebiendo con otros amigos y ya relajados, el método y "unas pocas copas" nos llevaban a aburrirlos con una ruidosa glosolalia.

-Joyce se ve tironeado por dos impulsos contradictorios. Quiere transformar al mundo en una gran taberna, sí, pero esa taberna no constituye un espacio social, sino que en ella solo se escucha la voz del autor. Nada de confidencias, diálogo, chismes... poca amabilidad.

- La voz del autor, además, es la de un simulador de voces, de modo que hay una representación acústica y tipográfica convincente. Uno cree estar oyendo y leyendo voces distintas, pero en el Finnegans Wake Joyce les hace una broma pesada a los jesuitas: no imita a dios sino al diablo. (Feiling 2005: 122)

El método con que Feiling y Chitarroni traducían se llamaba "El sistema de la doble humillación": la primera era la que les imponía Joyce, déspota de la lengua y de la memoria; la segunda consistía en someter sus hallazgos (palabras como "muymuldito") al escarnio de otro poeta que tenía, con el irlandés, una "relación simpática plena": Leónidas Lamborghini.

El nombre de Lamborghini importa, en esta historia que comienza con Pablo de Tarso. Fue Leónidas quien, en una de sus reescrituras, titulada "Pablo", retorció al infinito la Primera Epístola a los Corintios, el texto mismo en que el Apóstol critica el uso excesivo de la palabra ebria, de la glosolalia sin diermeneutés a la vista: "destruiré por: pues. Plugo plugo a. por la locura / destruiré la: a la. a. destruiré. ¿dónde están?. de los: la / sabiduría. Plugo que: discierne: y a él no. a..." (2011: 89; publicado por primera vez en 1996 en Las reescrituras, en la sección "La palabra en la hoguera"). Leónidas también reescribe el grito sagrado del Himno Nacional ("oíd lo que se oye") en su poema Seol, donde "disemina el texto de López y Planes, retirando de él una galaxia de cuerpos lacerados" (Antelo 2008: 43), y recapitulando todos los manejos vanguardistas sin coincidir con ninguno de ellos. Pero el nombre Lamborghini importa, también, por Osvaldo, quien no solo inventa la lengua comarquí, sino que también se solaza en cierto fonocentrismo, en cierta impostación de la voz: la voz sentenciosa, la voz de castrato (que reencontraremos en el Aira de Canto Castrato) con sus "paradojas en falsete", la voz arcaizante, la inflexión agauchada o la voz del borracho -en los Hechos de los Apóstoles, a quienes hablan en glosas se los acusa de estar hartos de licor-. En Osvaldo Lamborghini, como en las glosolalias según Agamben, la literatura "coincide más bien con el instante [...] donde la voz se articula en el lenguaje" (13), es decir, donde también se separa de él para dejar, en el medio, el gruñido-chillido de un tadey.

\section{Glosolalias transplatinas}

Este número de Cuadernos LIRICO presenta doce artículos agrupados en tres secciones. 

panorama histórico que comienza con las glosolalias religiosas en los albores de la era cristiana y continúa con la transformación del hablar en lenguas en la era del desdiosamiento, en su apropiación por la ciencia y las vanguardias. A continuación, Carmen Galán Rodríguez explora las lenguas artificiales y los universos femeninos, a partir de la ignota lingua de Hildegard von Bingen, la lengua interior de Friederike Hauffe y las lenguas marcianas y el sanscritoide de Hèlène Smith, demostrando que las experiencias glosolálicas son indisociables de la invención de un espacio de enunciación liberadora de la voz femenina. neocriollo de Xul Solar. En el primero, Pablo Gasparini compara las experimentaciones lingüísticas de Xul en San Signos y de Oliverio Girondo en En la masmédula a partir del contexto vanguardista y de los conflictos de este con el proceso inmigratorio argentino. En el segundo, Jorge Locane propone un análisis del neocriollo y del portunhol selvagem, lengua literaria que resulta de la mezcla del español, el portugués y el guaraní y que desde mediados de los años 80 se viene cultivando en la zona de la frontera sur de Brasil, con epicentro en la Triple Frontera. En la misma sección, Juan Cristóbal Castro, partiendo de la hipótesis de que la escritura es indisociable de los artefactos y dispositivos que la vuelven materialmente posible, explora la invención del glíglico y el neofonema cortazarianos, y la impronta que deja en ellos el uso de la máquina de escribir. Didier Coste, por su parte, comenta los procedimientos mediante los cuales Bernardo Schiavetta escribió su poema Almiraphel, texto políglota que asume sin reservas la maldición y el sinsentido de Babel. Finalmente, Julio Prieto examina las escrituras ilegibles de Mirtha Dermisache y León Ferrari, explorando cómo estas prácticas biblioclastas e ilegibilizantes, al trabajar el dibujo de la escritura, fabrican objetos lingüísticos sin palabras y hacen emerger, entre estética y política, una semiosis de la falta.

La sección "Archifilología, filosofías del lenguaje y lingüistería" está dedicada a los imaginarios y a las ficciones lingüísticas en la Argentina del siglo XX. Diego Bentivegna se centra en dos publicaciones de comienzos de la década de 1930: el Silabario de la decoración americana, de Ricardo Rojas y el Diccionario etimológico del castellano usual, de Leopoldo Lugones, como materializaciones de dos programas glotopolíticos alternativos que operan en el plano de la construcción de imaginarios latinoamericanos de la lengua. Raúl Antelo estudia el diseño glosolálico de la lengua de Girondo. Trama, para ello, una constelación de lo decible y de lo visible en que textos del poeta tales como los "Casos locuras interesantes" conectan con un cuadro de Goya exhibido en Buenos Aires: "Escena de combate". La lengua se corrompe en podrelengua en lo que va de Girondo a Goya, de Girondo a Pasolini (Salò) o a Perlongher ("Hay cadáveres"), descomposición que podría llegar hasta la charogne de Baudelaire o la carroña última forma de Leónidas Lamborghini. A continuación, Pablo M. Ruiz lee la literatura de Borges como una "poética del lenguaje". El lenguaje es la singularidad, la diferencia, la intensidad borgeana, lo que sugiere conexiones con escritores que llevaron el lenguaje a sus últimas consecuencias, como James Joyce. Martín Arias recorre las ficciones lingüísticas de Borges y de $\mathrm{O}$. Lamborghini a través de la distinción, postulada por los filósofos, entre "lingüistas privados" y "lingüistas públicos", mientras Diego Vecchio reflexiona sobre el "signo ebrio" de Héctor Libertella, que irrumpe, en la segunda mitad del siglo XX, en el cruce de la literatura, la lingüística y el psicoanálisis lacaniano, 
planteando la utopía de un signo lingüístico que sale de sus goznes para decir lo que no se puede decir, decir lo contrario de lo que dice, contornear el estallido de la vacuidad. El lenguaje está irremediablemente agujereado.

\section{BIBLIOGRAPHY}

Agamben, Giorgio, “La voz humana”, Nombres, revista de filosofía º28, año XXII, Córdoba, 2014. Traducción de Franca Maccioni de "La glossolalie comme problème philosophique", Discours psychanalytique $\mathrm{n}^{\circ}$ 6, París, 1983.

Aira, César, “El test. Una defensa de Emeterio Cerro”, Babel nº 8, marzo de 1989, p. 36.

Antelo, "La armonía grotesca de Babel”, Punto de vista n 90, abril de 2008, Buenos Aires, p. 38-44.

Artaud, Antonin, CEuvres complètes, vol. 9, Paris, Gallimard, 1971.

Biblia de Jerusalén, Bilbao, Desclée de Brouwer, 1999.

Carrera, Arturo, “Tejidos esponjosos”, Xul n³, diciembre 1981, p. 29-33.

Carrera, Arturo y Cerro, Emeterio, Retrato de un albañil adolescente \& Telones zurcidos para títeres con himen, Buenos Aires, Ediciones Último Reino, 1988.

De Campos, Haroldo, Del arco iris blanco, Buenos Aires, Adriana Hidalgo, 2006. Traducción de Amalia Sato.

Feiling, C. E., Con toda intención, Buenos Aires, Sudamericana, 2005.

García, Ofelia, Otheguy, Ricardo y Reid, Wallis, "Clarifying translanguaging and deconstructiong named languages: A perspective from linguistics", Applied Linguistics Review Vol. 6, septiembre de 2015, p. 281-307.

Girondo, Oliverio, Obra completa, Raúl Antelo (ed.), Madrid, Allca XX, 1999.

Huidobro, Vicente, Altazor, Barcelona, Compañía Ibero Americana de Publicaciones, 1931.

Lamborghini, Leónidas, El genio de nuestra raza. Las reescrituras de Leónidas Lamborghini, Buenos Aires, Ediciones Stanton, 2011.

Perlongher, Néstor, Papeles insumisos, Buenos Aires, Santiago Arcos, 2004.

Premat, Julio, Héroes sin atributos, Buenos Aires, Fondo de cultura económica, 2009.

Rosa, Nicolás, Relatos críticos, Buenos Aires, Santiago Arcos, 2006.

Rubione, Alfredo, “Xul Solar. Utopía y vanguardia”, Punto de vista n²9, julio de 1987, Buenos Aires, p. 37-39.

Sarlo, Beatriz, Borges: un escritor en las orillas, Buenos Aires, Ariel, 1995.

Scholem, Gershom, Major Trends in Jewish Mysticism, Nueva York, Schocken Books, 1995.

Schwartz, Jorge, Las vanguardias latinoamericanas: textos programáticos y críticos, Madrid, Cátedra, 1991. 
---, "Sílabas las estrellas compongan: Xul y el neocriollo", Xul Solar, Visiones y revelaciones (catálogo de exposición), Buenos Aires, Malba (Colección Costantini), 2005.

Swedenborg, Emanuel, Del cielo y el infierno, Madrid, Ediciones Siruela, 2002. Traducción de María Tabuyo y Agustín López.

Vallejo, César, Trilce, Lima, Laberintos, 2007.

Xul Solar, Los San Signos. Xul Solar y el I Ching, Buenos Aires, El Hilo de Ariadna, 2012. 